\title{
Application of Green Building Design in Residential Buildings
}

\author{
Wen Zhang* \\ Xiong'an Urban Planning and Design Institute, Xiong'an New District 071000, Hebei Province, China \\ *Corresponding author: Wen Zhang, 18706393771@163.com
}

\begin{abstract}
In recent years, with the rapid development of the world economy, the environment and resources have been seriously damaged, and the global climate is changing quietly. People began to pay more and more attention to the protection of environment and resources. In the process of building residential buildings, the construction industry also needs to strengthen the application of green building design, so as to achieve the purpose of green environmental protection. The author makes an in-depth research and analysis on the characteristics of green building design, and puts forward the effective strategies for the application of green building design in residential buildings, hoping to help improve the green environmental protection of residential buildings.
\end{abstract}

Keywords: Green building design; Residential buildings; Application strategy

Publication date: November 2021; Online publication: November 30, 2021

\section{Introduction}

Green building design not only has the characteristics of energy conservation and emission reduction, but also has the characteristics of sustainability and returning to nature. It has high application value in residential buildings. With the continuous development of society, people's requirements for residential buildings are also improving, especially the green and environmental protection of buildings. If construction enterprises want to develop in the long run, they must strengthen the application of green building design.

\section{Characteristics of green building design}

\subsection{Characteristics of sustainability}

In the new era, China pays more and more attention to sustainable development. From the actual situation of China's development in recent years, the sustainable development process of the construction industry is relatively slow. The main reason for this situation is the lack of balance in China's economic development. Construction industry is an important pillar industry of China's economic development. Therefore, it is very necessary to speed up the process of sustainable development of construction. And the green building design is more consistent with the basic indicators of modern social life. Green building design is the rational use of materials to promote the circular development of resources on the earth, so as to provide resources for people's production and life. Thus, green building design has the characteristics of sustainability.

\subsection{Characteristics of energy conservation and emission reduction}

From the current situation of China's development, energy conservation and emission reduction are a basic demand of modern development. How to achieve scientific energy conservation and reduce waste emission 
has always been a key research content of relevant disciplines. Green building design is conductive to the realization of energy conservation and emission reduction. Through the scientific allocation of building construction materials, we can rationally distribute construction materials and construction equipment, always take energy conservation and emission reduction as the center of each process of building construction, establish the awareness of environmental protection and strengthen the use of green construction materials, so as to further sublimate the concept of green building design, and better realize energy conservation and emission reduction.

\subsection{Characteristics of returning to nature}

A key content of green building design is to return nature. In the past, most architectural engineering design in our country did not have this feature. Green building design can promote the building to adapt more to the natural environment. In recent years, with the continuous development of society, there are more and more farmhouse and riverbank buildings. These buildings can not only create certain benefits for residents, but also promote the return of buildings to nature and integrate with nature, so as to give full play to their own value. Figure 1. is the design drawing of a farmhouse building.

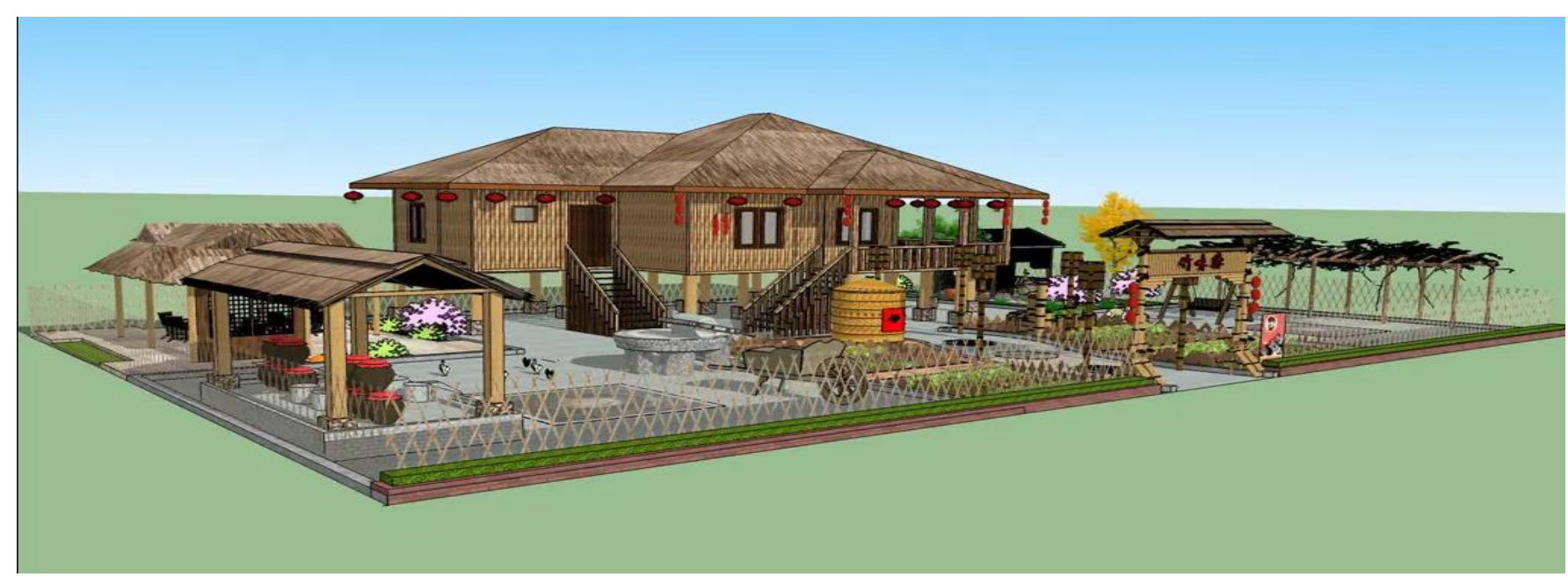

Figure 1. Design drawing of farmhouse building

\section{Basic principles of application of green building design in residential buildings 3.1. Basic principles of saving energy and reducing loss}

The application of green building design in residential buildings should aim at improving the quality of life of residents and meeting the needs of efficient and healthy life of residents. In the process of specific design, we must pay attention to strengthening the efficient utilization of resources, strive to recycle various resources, and strengthen the use of renewable resources and degradable resources, but we cannot destroy the residents' sense of living experience at the cost. Therefore, the application of green building design in residential buildings must follow the basic principles of saving energy and reducing loss, so as to realize the harmonious and sustainable development among architecture, environment and economy.

\subsection{Basic principles of health and comfort}

When applying the green construction design concept in residential buildings, we must follow the basic principles of health and comfort, and strive to create a livable ecological environment for residents, so as to improve the quality of life of residents and provide them with a more comfortable living and leisure space. In the specific design, in addition to ensuring the appropriate humidity, it is also necessary to ensure the adequacy of day lighting, so as to ensure the comfort of residents in the house. The application of green building design and the increase of green landscape can not only provide residents with a more beautiful 
living environment, but also purify the air and create a more comfortable environment for residents. For example: When integrating the green building design concept into the design of the basement roof of a residential building, we should not only pay attention to preventing the impact of flood disasters on residential buildings, but also pay attention to collecting rainwater, so as to realize the secondary utilization of rainwater. For example: We can collect rainwater to wash the toilet and irrigate green plants. Figure 2. is the basic design drawing.

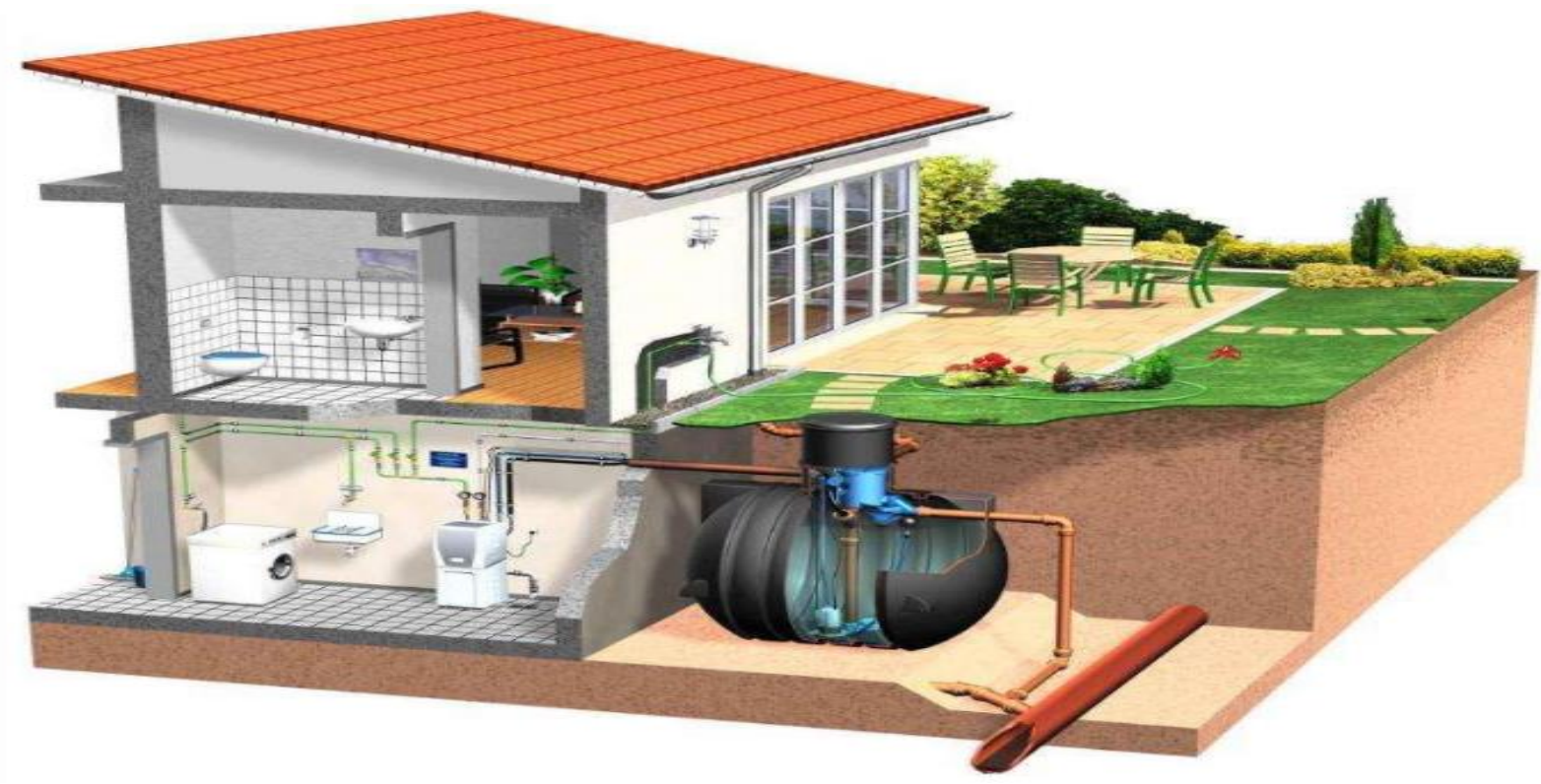

Figure 2. Design drawing of roof rainwater collection and secondary utilization

\subsection{Basic principles of economy}

Green building design concept needs to run through the whole process of residential building construction. Only in this way can we better achieve the goal of reducing energy consumption and pollution. This requires strengthening the utilization of non-renewable resources in the process of designing residential buildings. In the application of green building design concept in the design of residential buildings, another basic principle that needs to be followed is economy. That is, in the construction of residential buildings, we should strictly control the construction cost and prevent unnecessary capital waste as much as possible. We should make full use of existing resources, while ensuring the quality of residential buildings, reduce capital investment and further improve the economic benefits of buildings.

\section{Strategies of application of green building design in residential buildings}

\subsection{Application of green building design concept in residential building site selection}

Before planning and designing residential buildings, developers usually have selected the specific construction address. Designers only need to go deep into the address selected by developers for survey and thorough investigation before designing residential buildings, and design a scheme consistent with the site and surrounding environment in combination with the actual situation and climate characteristics of the construction site and surrounding environment ${ }^{[1]}$. In addition, in the specific design, in order to further highlight the green building design concept, it is also necessary to comprehensively analyze the local natural resources, strengthen the research on the orientation and pattern of residential buildings, and avoid the impact on the surrounding environment.

\subsection{Strengthen the use of environmental protection building materials}

The construction of residential buildings is composed of various building construction materials. In the 
process of applying the green building design concept to the design of residential buildings, we must reasonably select building materials, so as to achieve the effect of environmental protection while reducing energy consumption and fully realize the ecological value of green building design ${ }^{[2]}$. When selecting building materials, in addition to strictly controlling the quality of materials, we also need to pay attention to improving the utilization rate of building materials and reducing unnecessary waste of resources, so as to improve the quality of residential buildings. For example: Aluminum silicate is a new environmental protection building material. It not only has good fireproofing and waterproofing quality, but also can absorb excess heat. Compared with traditional building materials, this environmental protection building material has its own unique advantages and can improve the green environmental protection of residential buildings. Figure 3. shows aluminum silicate building materials.

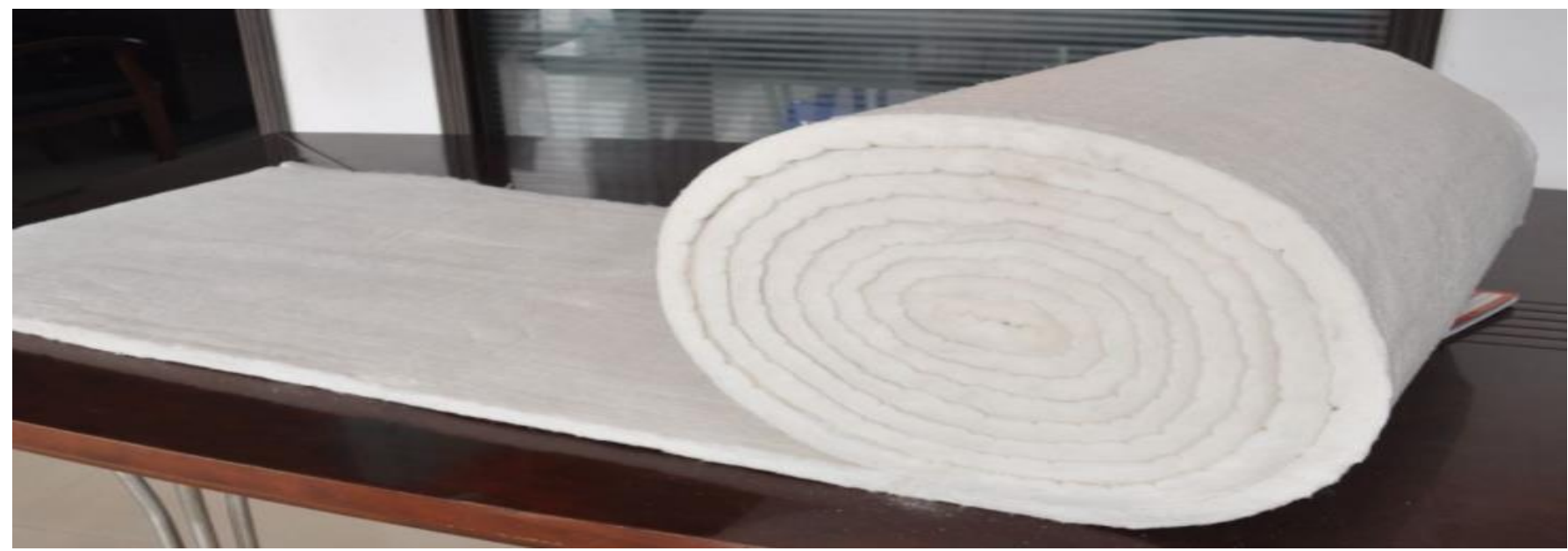

Figure 3. Aluminum silicate building materials

\subsection{Application of green building design concept in residential building structure design}

In recent years, China pays more and more attention to the development of the construction industry. At the same time, it also puts forward new requirements for the development of the construction industry, requiring construction enterprises to strengthen the application of green building design concept when designing residential building structure ${ }^{[3]}$. Our government proposes to widely use solar energy. When designing green residential buildings, we also need to actively implement the requirements of our government, strengthen the utilization of solar energy, and apply solar panels to residential buildings, so as to achieve the purpose of energy conservation. Figure 4. shows the solar panels used in residential buildings. As we all know, solar energy is a renewable energy resource. Solar energy can be converted into electric energy through solar panels for residential residents. At the same time, solar panels can also be used to convert solar energy into heat energy, so as to provide hot water for residents in the building.

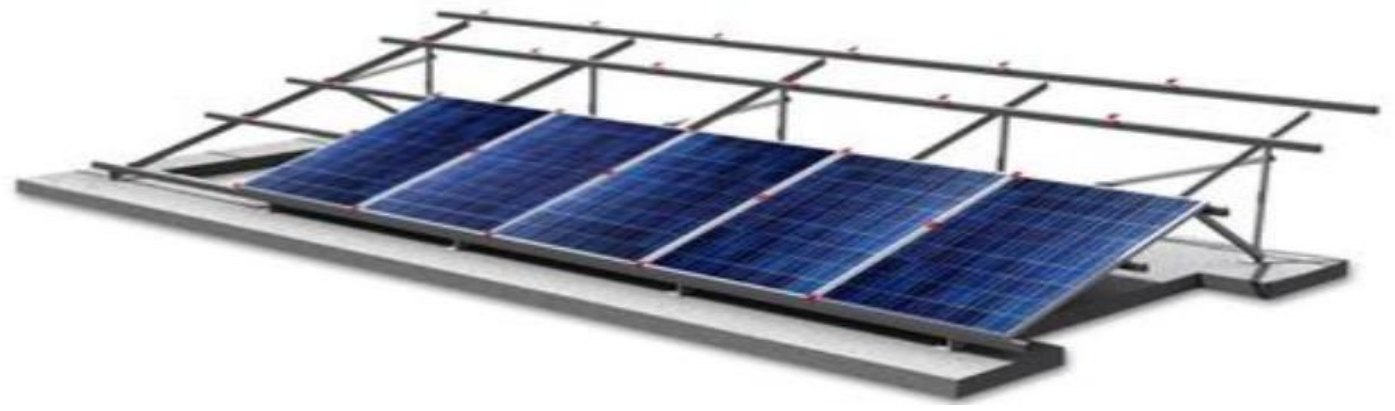

Figure 4. Solar panels 


\subsection{Strengthen the utilization of the surrounding environment}

When applying green building design in residential buildings, we must strengthen the utilization of the surrounding environment. Carbon dioxide will cause certain damage to human body, while plants can well absorb carbon dioxide in the air and achieve the effect of purifying the air ${ }^{[4]}$. Therefore, when applying the green building design concept to the design of residential buildings, we should integrate it with the surrounding environment, which can not only reduce the air pollution, but also create a comfortable environment for the residents in the residential buildings. In the process of specific design, designers should not only strengthen the utilization of the surrounding environment, but also pay attention to the greening design in residential buildings with the help of natural advantages. They can appropriately plant more green plants in the residential area and expand the green planting area of the residential area, so as to create a beautiful small park environment for the large number of residents. The planting of green plants can not only beautify the environment, but also purify the air, cultivate the mind of residents, and create a comfortable and fresh living environment for residents. In recent years, the number of high-rise residential buildings has gradually increased. High-rise buildings can not only meet the living needs of residents, but also save land resources. When applying the green building design concept to design high-rise buildings, designers can choose to plant some plants that can climb along the wall, so as to increase the green area of the residential area and improve the ecological environment of the residential area. In summer, green climbing plants can also absorb a certain amount of sunlight, which can achieve the effect of adjusting indoor temperature, so as to create a more comfortable environment for residents. Figure 5. shows climbing plants in high-rise residential buildings.

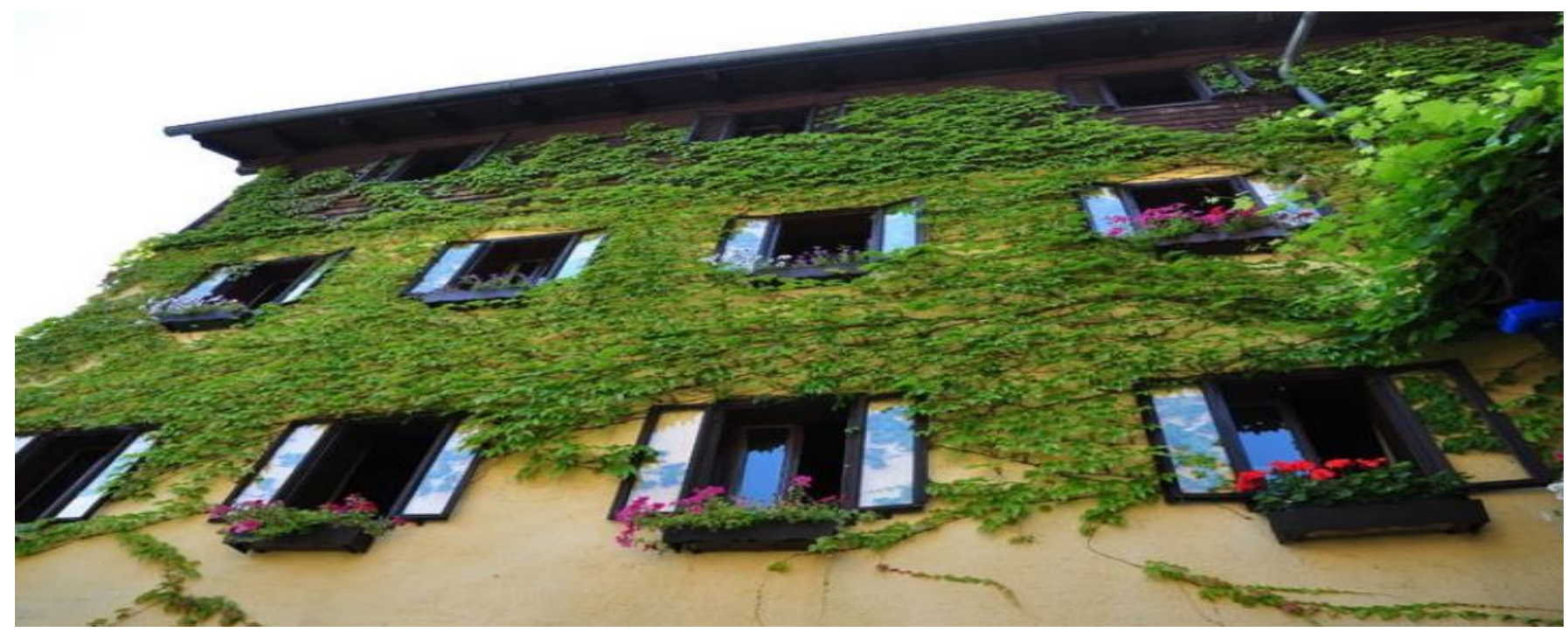

Figure 5. Climbing plants in high-rise residential buildings

\subsection{Pay attention to improving the natural ventilation effect of residential buildings}

Although air conditioning has a good effect on regulating the indoor temperature and humidity of residential buildings, the use of air conditioning will not only consume a lot of electric energy, but also cause certain air pollution. Therefore, when applying the green building design concept to design residential buildings, we should pay attention to improving the natural ventilation effect of residential buildings, so as to replace the use of air conditioning, create a natural air environment for residents in the buildings, and this can also reduce energy consumption, reduce air pollution as well as ensure the physical and mental health of residents. In order to achieve the effect of natural ventilation, it is necessary for designers to comprehensively consider various factors when designing residential buildings, including the climate 
conditions, topography, dominant wind direction and trees and vegetation, so as to achieve the effect of natural ventilation more reasonably. Moreover, it is also necessary to scientifically design the house type of residential buildings to form natural wind convection indoors, and regulates the temperature of the building by taking some of the heat away from it through the draught. This can not only accelerate the flow of air in the building, but also promote the exchange of indoor and outdoor air, so as to create a more comfortable indoor air environment for residents ${ }^{[5]}$.

\section{Conclusion}

To sum up, the construction industry plays a good role in promoting China's social and economic development. In the process of constructing traditional buildings, not only resources are wasted, but also the surrounding environment may be polluted to a certain extent, which is very unfavorable to the construction industry and the realization of the national sustainable development goal. Therefore, in the process of designing residential buildings, we must establish the concept of green and environmental protection and strengthen the application of green building design. On one hand, we should avoid unnecessary energy loss and improve the utilization rate of resources, on the other hand, we should prevent pollution to the surrounding environment and to achieve the purpose of environmental protection. In the process of applying the green building design concept to the design of residential buildings, it is also necessary to strengthen the use of green, environmental protection and renewable energy, so as to further improve the energy-saving and environmental protection effect of residential buildings.

\section{Disclosure statement}

The author declares no conflict of interest.

\section{References}

[1] Chen X, 2021, Application of Green Building Concept in Prefabricated Residential Building Design. Anhui Architecture, 28(06): 75+86.

[2] Zhang T, 2021, Research on the Application of Green Building Design in High-rise Residential Building Design. Home, (11): 94-95 + 101.

[3] Teng J, Li C, 2020, Application of Green Building Design Concept in Residential Building Design in Cold Region. Housing and Real Estate, (33): 70+72.

[4] Li Z, Su X, 2020, Discussion on the Application of Green Building Design in Civil Residential Building Design. Management and Technology of SME (Mid Term), (09): 180-181. 